\title{
A TEORIA MARXISTA DA DEPENDÊNCIA À LUZ DE MARX E DO CAPITALISMO CONTEMPORÂNEO
}

\author{
Carlos Eduardo Martins*
}

\begin{abstract}
Neste artigo, analisam-se as principais contribuições da economia política da dependência a partir dos debates que a obra de Ruy Mauro Marini suscitou. Propõe-se a reformulação teórica dos conceitos de superexploração do trabalho e de subimperialismo, com o objetivo de atualizar e enriquecer a teoria marxista da dependência, para a análise das tendências do capitalismo contemporâneo e das formas históricas que ele assumiu na América Latina. O texto se divide em três partes: a primeira onde se expõem o pensamento de Marini e suas contribuições para a economia política; a segunda onde se apresentam as principais críticas realizadas ao seu enfoque; e a terceira onde se busca sustentar seu enfoque a partir de algumas reformulações que se consideram necessárias para desenvolvê-lo.

PALAVRAS-CHAvE: Superexploração do trabalho. Subimperialismo. Economia política marxista. Marini. Marx.
\end{abstract}

\section{APRESENTAÇÃO}

Neste artigo, propomo-nos a revisitar a economia política da dependência, tomando como eixo os debates relacionados à obra de Ruy Mauro Marini. Um dos principais temas de destaque da economia política latino-americana foi a existência ou não de leis específicas do capitalismo dependente, em particular quanto à pertinência dos conceitos de superexploração do trabalho e de subimperialismo. Buscamos, a partir de um balanço crítico da obra desse autor e das polêmicas por ela suscitadas, reformular alguns de seus conceitos, contribuindo para atualizar a teoria marxista da dependência como um instrumento de análise do capitalismo contemporâneo e das formas históricas que assumiu na América Latina.

Na primeira parte, apontamos os principais conceitos formulados por Marini na elaboração de uma economia política da dependência, contemplando sua extensão ao capitalismo

* Universidade Federal do Rio de Janeiro (UFRJ). Instituto de Relações Internacionais e Defesa.

Av. Pasteur $n^{\circ} 250$. Campus da Praia Vermelha. CEP: 22.290-

902. Urca - Rio de Janeiro - Brasil. cadu.m@uol.com.br central, defendida pelo autor a partir da globalização do padrão de acumulação neoliberal.

Na segunda parte, apresentamos algumas das principais críticas que seu enfoque sofreu, tanto as oriundas do desenvolvimentismo em seus diversos matizes quanto aquelas formuladas dentro da própria teoria marxista da dependência. Na terceira parte, interpelamos a obra de Marini a partir do diálogo com essas críticas, sustentando seu enfoque a partir de reformulações que consideramos indispensáveis para seu desenvolvimento e atualização histórica.

\section{MARINI E A ECONOMIA POLÍTICA DO CAPITALISMO DEPENDENTE}

Marini formulou o conceito de superexploração pela primeira vez, de forma mais sistemática, em Dialética da dependência (1973), que ampliou Dialectica de la dependencia: la economia exportadora (1972) - publicado incialmente como artigo na revista Sociedad y desarrollo, editada pelo Centro de Estudios Socio-Económicos (CESO) no Chile - para analisar as etapas da industrialização na América 
Latina, acrescentando-lhe um post scriptum. ${ }^{1}$ As teses de Dialética da Dependência (1973) foram desenvolvidas posteriormente, durante os anos 1970, em dois artigos, Plusvalía extraordinária e acumulación de capital (1979) - que o autor considera complemento indispensável ao seu livro - e El ciclo del capital en la economia dependiente (1979). Nos anos 1990, ao coordenar, no Centro de Estudios latinoamericanos de la Universidad Autónoma do México (CELA/UNAM), um balanço das contribuições do pensamento latino-americano durante a transição para o padrão de acumulação neoliberal que se impunha na região, o autor postulou, em Tendencias y processos de La globalización capitalista (1996), a extensão, aos países centrais, da superexploração do trabalho, que considera constitutiva do capitalismo dependente, em razão das mudanças introduzidas na divisão internacional do trabalho e nos padrões globais de acumulação.

Ao desenvolver o conceito de superexploração do trabalho, Marini considerou necessário ir além do ponto de partida de Marx para a formulação do conceito de mais-valia, de que para o conjunto da classe trabalhadora, no longo prazo, desprezando-se as oscilações conjunturais, o preço da força de trabalho equivale a seu valor. Postulou, então, a existên$\infty$ cia de duas grandes formas de exploração do

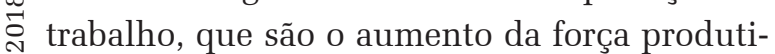
凶ં va do trabalho, vinculada à elevação da produividade, e a maior exploração do trabalhador, que constitui a superexploração. Essa última se define pelo aumento da jornada de trabalho ou da intensidade de trabalho, sem a remuneração equivalente do trabalhador, ou pela apropriação de parte do seu fundo de consumo, implicando redução salarial e violação de uas condições de existência. No seu conjunto, a superexploração do trabalho significa a queda dos preços da força de trabalho, abaixo de

mbém eito de superexploração do trabalho apareceu (1968) e, de forma mais destacada, em La acumulación capitalista dependiente y La superexplotación del trabajo (1972), resultado de sua intervenção no encontro de economistas latino-americanos e italianos em Roma. seu valor, implicando maior desgaste e redução de sua vida útil.

A maior exploração do trabalhador, todavia, não se restringe, segundo Marini, a situações onde o aumento da produtividade é irrelevante ou inexistente. Ele aponta que essas duas formas de exploração não se excluem, mas se articulam, tendendo a se compensar no conjunto da economia mundial capitalista, pois o aumento da força produtiva do trabalho cria a possibilidade de maior exploração do trabalhador, conduzindo, efetivamente, a esse resultado. Isso é assim porque o aumento da força produtiva do trabalho não possibilita apenas a elevação da taxa geral de mais-valia e a mais-valia relativa, mas também a mais-valia extraordinária e a apropriação de mais-valia. O aumento da força produtiva do trabalho apenas se converte em mais-valia relativa quando reduz o valor da força de trabalho, barateando os bens de consumo necessários, diminuindo o tempo de trabalho necessário e elevando os salários. Isso ocorreria quando a competição intercapitalista assim o impusesse, e as lutas dos trabalhadores garantissem um aumento do seu poder de consumo e a redistribuição parcial do excedente em seu favor. Mas o aumento da força produtiva do trabalho poderia implicar mais-valia extraordinária, objetivo primordial do capitalista individual, levando ao emprego da maior exploração do trabalhador pelos capitais que não pudessem neutralizá-la por meio da inovação tecnológica.

Em razão da forma como se inserem no ciclo de reprodução ampliada do capital na economia mundial, as burguesias dos países dependentes, inscritas de maneira subordinada na divisão internacional do trabalho, recorreriam regularmente à maior exploração do trabalhador como forma de compensar as transferências de mais-valia determinadas pelo monopólio tecnológico dos países centrais. Estas transferências se apresentam associadas a distintos contextos históricos e a padrões de reprodução do capital. Marini aponta que o emprego da maior exploração do trabalhador 
nos países dependentes ocorreria em função dos fatores a seguir apresentados:

a) Da busca do lucro extraordinário por parte das oligarquias dirigentes, na velha economia primário-exportadora, que, impulsionada pelo mercado mundial, mas limitada pela baixa produtividade, as levaria a recorrer ao aumento da jornada de trabalho para atender às pressões de demanda dos países centrais.

b) Da introdução do desenvolvimento tecnológico associado ao capital estrangeiro no setor exportador, implicando a desvalorização de mercadorias que não se dirigem preferencialmente ao consumo dos trabalhadores nacionais - mas ao da burguesia e dos trabalhadores dos países centrais e das oligarquias e camadas médias locais - e a repartição desigual da massa de mais-valia nesse segmento, em função da elevação da heterogeneidade tecnológica imposta pela fixação dos preços de produção. Assim, de um lado, a elevação da composição orgânica do capital soma-se à desvalorização das mercadorias, com efeitos marginais sobre a taxa de mais-valia - o que contribui para reduzir a taxa de lucro- e, de outro, o monopólio tecnológico reparte desigualmente a massa de valor em detrimento dos capitais de menor composição técnica.

c) Da introdução da tecnologia estrangeira e do monopólio tecnológico no setor industrial, que se orienta preferencialmente para o setor de bens de consumo suntuários, estabelece escassa relação entre a desvalorização das mercadorias e a da força de trabalho, e desloca o valor de mercado em direção aos capitais de maior composição técnica do segmento.

d) Da fixação da mais-valia extraordinária como componente interno estrutural do capitalismo dependente, em função do monopólio tecnológico estabelecido pela entrada da tecnologia estrangeira. A mais-valia extraordinária se estabelece não apenas dentro dos ramos produtivos, mas também no plano intersetorial, violando os preços de produção, ao impor, com a substituição da força de trabalho por maquinaria, transferências de valor em favor do setor de bens de consumo suntuário, convertendo parte da demanda dos trabalhadores em mais-valia não acumulada, isto é, em demanda dos que vivem do gasto de excedente.

e) Das remessas de capital por parte das empresas estrangeiras internalizadas nos países dependentes às suas matrizes, motivadas por seu planejamento estratégico mundial, pelo baixo nível de competitividade local e pelas restrições relativas ao investimento impostas pela superexploração do trabalho.

f) E, finalmente, ela deriva do estabelecimento da mais-valia extraordinária no comércio internacional em favor dos monopólios empresariais sediados nos países centrais, em razão, com o desenvolvimento da divisão internacional do trabalho, da contradição entre a transferência tecnológica crescente para os países dependentes, destinada à produção de partes, componentes ou produtos de menor complexidade, e a economia relativa desse consumo pelos monopólios tecnológicos e consumidores dos países centrais.

A superexploração do trabalho surge, assim, essencialmente como recurso de compensação às transferências de valor intrassetoriais e intersetoriais por parte de capitais que estão abaixo das condições médias de produção, internas e internacionais, e que empregam a maior parte da força de trabalho de seus países, determinando-lhes os marcos gerais do mercado de trabalho. Segundo o autor, a superexploração do trabalho tenderia a obstaculizar o trânsito da mais-valia absoluta para a relativa como forma dominante de acumulação e engendraria sua forma própria de mais-valia relativa: o aumento da intensidade do trabalho, sem a remuneração equivalente ao maior desgaste da força de trabalho, o que, ao se generalizar, rebaixa seu valor histórico moral e eleva o tempo de trabalho excedente. A superexploração exigiria a presença de altos níveis de desemprego e subemprego para que os preços da força de trabalho se nivelassem 
abaixo de seu valor, e democracias limitadas ou regimes políticos ditatoriais que impusessem tal situação.

Os padrões de acumulação do capitalismo dependente estariam marcados por forte concentração de renda e de propriedade e seriam liderados pelas frações burguesas concentradas nos setores primário-exportadores, de bens de consumo suntuário ou financeiros. Haveria restrições ao investimento produtivo no mercado interno aos segmentos orientados para os bens de consumo necessários, que sofreriam concentração e monopolização precoce e cujo dinamismo se vincularia, em parte, ao mercado internacional.

Marini menciona que o mercado interno, impulsionado pelo consumo de bens suntuários e pela demanda estatal, seria relativamente insuficiente para atender à dinâmica de investimento industrial dos países dependentes que tivessem atingido composição orgânica média e a etapa do capital financeiro, fomentando, neles, tendências subimperialistas. Tais tendências se manifestariam na exportação de mercadorias ou de capitais, em busca de matérias-primas ou de controle de mercados, e no estabelecimento de projetos geopolíticos para países periféricos e regiões, mas sua oportunidade estaria condicionada a espaços e conjunturas em que fossem menores os obstáculos

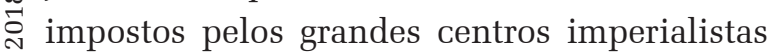
¿ e suas empresas. Para Marini, poucos países poderiam jogar um papel subimperialista, cabendo essa possibilidade, na América Latina, ao Brasil. O subimperialismo, para além de um esquema econômico de realização que saltaria limitações do mercado interno, teria sua plena configuração em um projeto de autonomia na dependência, que se expressaria na busca do desenvolvimento da indústria pesada - onde poderia ganhar destaque a militar -, do estabelecimento de centros internos de decisão e da ascensão nas hierarquias de poder e cadeias produtivas internacionais. Todavia sua incapacidade para romper com os vínculos financeiros, tecnológicos e políticos do imperialismo e de assentar seu modelo de acumulação sobre o aumento dos preços e a desvalorização da força de trabalho, para dar lastro à sua pretensão de autonomia, limitaria fortemente sua capacidade de expansão (Cf. Marini, 1974, 1977a, 1978).

Nos anos 1990, Marini afirma que a superexploração do trabalho estaria deixando de ser uma característica exclusiva da acumulação nos países dependentes, ao se estender aos países centrais. Os processos de globalização criariam novas fontes de mais-valia extraordinária ao deslocar o monopólio da tecnologia para a ciência e fragmentar a fabricação do produto em partes e componentes, orientando-a para mercados mundiais e permitindo combinar a alta tecnologia e a força de trabalho superexplorada da periferia para substituir parcialmente a produção realizada nos países centrais (Marini, 1996). Dessa forma, com o novo desenho organizacional das corporações transnacionais, os salários da periferia passariam a nivelar para baixo os do centro, e as empresas de base estritamente nacional desse cairiam a níveis inferiores aos das condições médias de produtividade dos mercados internacionais, levando-as a empregar a maior exploração do trabalhador.

\section{CRIITICAS E DEBATES}

As críticas ao pensamento de Marini se originaram de diversas fontes, sendo as mais antagônicas as que partiram do enfoque weberiano da dependência, do neodesenvolvimentismo e do endogenismo. Outras críticas têm partido do próprio campo da teoria marxista da dependência que, estimuladas pela ascensão das esquerdas na América Latina no século XXI, buscam maior precisão nos marcos conceituais paradigmáticos lançados por Marini. Tais marcos, situados em alto nível de abstração, são introdutórios e gerais, suscetíveis de posterior desenvolvimento, como o autor reconhece no post scriptum de Dialética da dependência: 
Dialéctica de la dependencia no pretende ser sino esto: una introducción a la temática de investigación que me viene ocupando y de las líneas generales que me orientan en esa labor. Su publicación obedece al propósito de adelantar algunas de las conclusiones a que he llegado, susceptible quizá de contribuir al esfuerzo de otros que se dedican al estudio de las leyes de desarrollo del capitalismo dependiente, así como al deseo de darme a mí mismo la oportunidad de echar una ojeada global sobre el terreno que intento desbrozar.

Aprovecharé, pues, este post scriptum para aclarar algunas cuestiones y deshacer ciertos equívocos que el texto ha suscitado. En efecto, pese al cuidado puesto en matizar las afirmaciones más tajantes, su extensión limitada llevó a que las tendencias analizadas se pintaran a brochazos, lo que les confirió a veces un perfil muy acusado. Por otra parte, el nivel mismo de abstracción del ensayo no propiciaba el examen de situaciones particulares, que permitieran introducir en el estudio cierto grado de relativización (Marini, 1973, p. 81-82).

A principal crítica formulada pelo enfoque weberiano da dependência foi feita isoladamente por Fernando Henrique Cardoso, ou em trabalho conjunto com José Serra, expoente do pensamento neodesenvolvimentista brasileiro. Cardoso descarta a proposta teórica de Marini, respaldada por Theotonio dos Santos e Vânia Bambirra, de que existiriam leis de movimento especificas para o capitalismo dependente, argumentando que isso só poderia ocorrer caso este representasse um modo de produção específico (Cf. Cardoso, 1975, 1979, 1993). Para Cardoso, o capitalismo industrial estaria baseado na mais-valia relativa e na expansão da produtividade, condicionando as novas formas de dependência que o internalizavam, ou suas tecnologias, a partir dos anos 1950, na América Latina. Cardoso aponta que a superexploração poderia ocorrer em situações específicas, independentes da dinâmica do moderno capitalismo dependente. Elas seriam oriundas de determinações políticas que atuassem sobre seus marcos estruturais e debilitassem a atuação dos trabalhadores na luta de classes, ou de articulações de modos de produção, entre o capitalismo e formas econômicas pré-capitalistas, que limitassem o desenvolvi- mento do primeiro. Cardoso destaca que, para analisar a dinâmica da dependência, a ênfase deve ser posta no conceito de desenvolvimento, uma vez que a dependência é condicionada pela expansão do capitalismo internacional (Cf. Cardoso, 2010). Ele descarta a formulação de uma teoria da dependência em favor de uma teoria global do desenvolvimento capitalista que daria os marcos da articulação de forças externas e internas, constituídas por classes sociais e grupos políticos, cuja interação definiria as formas concretas e particulares que este assumiria na periferia (Cf. Cardoso, 1979).

Cardoso e Serra, em sua análise das transferências internacionais de valor - tema que surpreendentemente descartam com o argumento de que a baixa mobilidade internacional de força de trabalho não permitiria medir o trabalho socialmente necessário -, acusam Marini de confundir intercâmbio desigual e deterioração dos termos da troca ${ }^{2}$ (Cf. Cardoso; Serra, 1978). Apontam que o intercâmbio desigual não atinge negativamente a taxa de lucro, enquanto a deterioração dos termos da troca só o faz quando a queda dos preços na periferia for independente das variações de produtividade. Afirmam que Marini sustentaria sua teoria da superexploração em condições de estagnação ou de produtividade decrescente do setor exportador na periferia. Apontam ainda que ele prioriza a taxa de mais-valia ao invés da taxa de lucro e negligencia o papel do barateamento do capital constante na recuperação desta taxa, indicando, para isso, apenas a redução dos custos da força de trabalho. Sua teoria da superexploração exigiria ainda, como condição, a estagnação produtiva no setor de bens de consumo necessários, desdobrando-se na busca de mercados externos, fundamento de sua teoria do subimperialismo. Assinalam que a produtividade concentrou-se no setor de ${ }^{2}$ Segundo Cardoso e Serra, o intercâmbio desigual se expressa nos diferenciais de produtividade entre os setores exportadores da periferia e do centro, em benefício desse último, sem impactos na variação dos preços das mercadorias de ambas as regiões; já a deterioração dos termos de troca implica não apenas diferenciais de produtividade em favor do centro, mas de preços, afetando-os negativamente na periferia, sem alterá-los nos centros (Cf. Cardoso; Serra, 1978). 
bens de consumo duráveis, mas avançou também no setor de bens de consumo necessários e, em ambos os casos, muito mais do que a extensão da jornada de trabalho. ${ }^{3}$ Para Cardoso e Serra, as contenções salariais realizadas pelos governos militares teriam sua determinação em seu reacionarismo, e não nas necessidades do capitalismo dependente. Concluem que o dilema socialismo ou fascismo, sustentado por Theotonio dos Santos, mas também por Marini, basear-se-ia na tese da estagnação do capitalismo dependente e que são escassas as bases empíricas apresentadas pelo autor para comprovar seu enfoque.

O texto de Cardoso e Serra constitui-se como paradigmático das interpelações neodesenvolvimentistas a Ruy Mauro Marini, Theotonio dos Santos, Vânia Bambirra e Andre Gunder Frank, negligenciando as críticas explícitas dos três primeiros à identificação entre dependência e situação colonial, presente no texto de Frank, $O$ desenvolvimento do subdesenvolvimento (1966), que subestima o desenvolvimento das forças produtivas e a autonomia formal do Estado nacional ${ }^{4}$ (Cf. Cardoso; Serra, 1978). Na mesma direção situa-se o texto de Gabriel Palma, que busca contrapor o enfoque da dependência, postulado pelo CESO aos escritos de Marx, e apresenta o livro Dependência e o desenvolvimento na América Latina (1967) de : Cardoso e Falleto, reforçado pelo prefácio de ब 1977, como fundador de um marco analítico đ capaz de perceber a dinâmica interna da de-

¿ ${ }^{3}$ Cardoso e Serra confundem a elevação da produtividade $\therefore$ com a mais-valia relativa, sem questionarem como afeta o

$\curvearrowright$ grau de exploração na economia, o valor dos bens-salários,

$>$ e se articula com a demanda. Mantega também o faz e cita

ธิ Desventuras para afirmar: "Aqui os dados são ainda mais

T eloquentes, pois mostram que a produtividade industrial

(não distribuída aos trabalhadores), representando a mais-

๙ -valia relativa, cresceu de 1959 a 1970 em 75\% [...] e a

I queda do salário real foi de 35\%" (Mantega, 1984, p. 271).

- A influência de Cardoso e Serra (1978), no Brasil, na lei-

$\bigcirc$ tura da obra de Marini e da vertente marxista da depen-

dência, está presente em textos como os de Luiz Carlos

Bresser Pereira (1982), Guido Mantega (1984) e Lidia Gol-

denstein (1994). troduzido pelo capitalismo europeu e, quando superada a fase de acumulação primitiva, eles poderiam ser integrados aos níveis mais avançados do desenvolvimento capitalista, pouco importando se o agente inicial fosse externo ou interno. Para Palma, a escola do CESO, de forma diametralmente oposta, negaria a possibilidade de desenvolvimento na dependência.

Agustín Cueva, em Problemas e perspectivas da teoria da dependência (1974) assinala que Marini estiliza as diferenças entre capitalismo clássico e dependente, e trabalha com modelos e não leis. Cueva aponta que as leis gerais do capitalismo são modificadas pela presença do imperialismo e pela articulação de modos de produção, mas que são modificações de grau e não de qualidade, e não dão lugar a nenhuma teoria da dependência. As diferenças entre formações sociais devem ser vistas mais nas articulações internas que nas internacionais entre países dependentes e industriais. ${ }^{5}$ Ele afirma que o conceito de subdesenvolvimento é mais explicativo sobre as restrições ao consumo da classe trabalhadora que o de superexploração, e pode se aplicar aos países centrais, como na França dos anos 1940. Destaca que, apesar de sugestivo, o conceito de superexploração apresenta inconsistências históricas, apontando, entre elas, a subestimação do alto consumo de carne pela população argentina e do consumo popular de produtos industriais na América Latina. Posteriormente, Cueva matiza suas afirmações em Las democracias restringidas de America Latina (1989), quando revisita o tema da superexploração, admitindo sua pertinência no plano histórico, ainda que não no teórico, o que se explica por um desvio imposto pelo imperialismo sobre as leis puras de desenvolvimento do capital. Todavia, se reconhece a pertinência da superexploração, Cueva aponta que o subimperialismo não se confirmou historicamente, acossado pela amplitude do imperialismo neoliberal (Cf. Cueva, 1989).

\footnotetext{
${ }^{5}$ Posição similar apresenta Hector Diaz Polanco em seus comentários ao artigo de Marini, El ciclo del capital em la
} economia dependiente (1979) (Cf. Polanco, 1979). 
Castañeda e Hett, que expressam variantes do pensamento neodesenvolvimentista e sustentam a hipótese da emergência de imperialismos latino-americanos, pretendem criticar os pilares do conceito de superexploração ao apontarem que não há base teórica para afirmar quando o preço da força de trabalho está abaixo de seu valor, pois tal valor seria fixado historicamente pelas lutas de classes e não abstratamente (Cf. Castañeda; Hett, 1978). De forma similar, Jose Valenzuela Feijoó, em um texto com erros grosseiros de exposição do pensamento de Marini, sustenta que os preços da força de trabalho são determinados pela realidade concreta e se, no longo prazo, descartarmos os ciclos de conjuntura, serão iguais ao seu valor ${ }^{6}$ (Cf. Feijoó, 1997). Mais recentemente, Claudio Katz sustentou a tese de uma dependência sem superexploração, defendendo que há baixos salários na periferia e não remuneração abaixo do valor da força de trabalho. O capitalismo periférico pagaria salários equivalentes ao baixo valor de uso ou troca da força de trabalho, atendendo a necessidades fisiológicas e histórico-sociais do trabalhador condicionadas por "produtividade, escala de acumulação, luta de classes e padrões culturais de cada país" (Katz, 2018, p. 2).

No campo mais próximo à teoria marxista da dependência, Cristóbal Kay destacou a importância do aporte de Marini, mas objetou que o autor nunca procurou formalizar matematicamente suas hipóteses, o que restringiu sua capacidade de demonstrá-las (Cf. Kay, 1989). Entre os temas que ganham relevância no debate sobre a superexploração está o de sua compatibilidade ou não com a mais-valia relativa, tal como foi assinalada por Marx, o que implica elevação da produtividade e barateamento dos bens salariais. Em publicação recente, ao avançarmos na questão da for-

${ }^{6}$ Veja-se, de Jose Valenzuela Feijoó, Sobrexplotación y dependência (1997), publicado meses após à morte de Marini. Entre os estranhos erros de interpretação do pensamento de Marini está o de lhe atribuir a afirmação de que os países da periferia possuem uma taxa de mais-valia superior aos do centro e que, nos últimos, há um nível maior de superexploração do trabalho, formulações totalmente alheias ao pensamento do autor. malização matemática da superexploração, apontamos que a hipótese da compatibilidade da superexploração com a mais-valia relativa deve ser analisada à luz dos padrões concretos de reprodução do capital e que não há elementos suficientes apresentados por Marini para afastar essa possibilidade. Assinalamos a necessidade de se avançar na reelaboração do conceito de superexploração, que aprofundaremos neste artigo, pois entendemos ser indispensável para desenvolver as formulações de Marini e ampliar seu alcance (Cf. Martins, 2017). Indicamos ainda a necessidade de se integrar, ao conceito de superexploração, uma quarta forma de maior exploração do trabalhador, referente ao aumento do valor da força de trabalho, associada à elevação de sua qualificação sem a remuneração equivalente. Afirmamos que essa quarta forma, apesar de não estar explicitada por Ruy Mauro Marini, surge em várias passagens de seus trabalhos (Cf. Martins, 2011, 2017).

Marcelo Carcanholo faz objeções ao termo superexploração do trabalho para nomear o conceito de Marini, considerando que o mais adequado é superexploração da força de trabalho, e questiona ainda a atribuição, por Marini, de mais-valia relativa ao aumento da intensidade do trabalho ${ }^{7}$ (Cf. Carcanholo, 2017). Ganha destaque ainda, no debate sobre a superexploração, a questão de sua extensão ou não aos países centrais, pois aqueles que defendem a extensão apontam a reestruturação da divisão internacional do trabalho e novas formas monopólicas e de mais-valia extraordinária como o seu determinante, e aqueles que a negam defendem a superexploração como uma especificidade do capitalismo dependente (Cf. Carcanholo, 2017; Osório, 2013).

Na próxima seção, faremos um balanço

${ }^{7}$ A contraposição dos termos superexploração da força de trabalho e trabalho nos parece equivocada e pouco dialética. Marini usa ambos, com predominância do segundo. Marx se refere tanto à exploração da força de trabalho assalariada e do trabalhador que é seu proprietário. A forma objetificadora em que a exploração se apresenta é parte das relações que o capital impõe, mas constitui apenas uma dimensão dessa totalidade, pois a exploração do trabalho pelo capital é a exploração entre sujeitos. 
crítico da obra de Ruy Mauro Marini para dialogar com as interpelações a ela dirigidas.

\section{PARA A REFORMULAÇÃO DA ECONOMIA POLÍTICA DA DEPEN- DÊNCIA}

Ruy Mauro Marini deixou uma obra de enorme fecundidade e criatividade, que avançou na direção do método dialético de Marx, orientando-se para o desdobramento do nível analítico mais abstrato ao mais concreto. Avançou do plano mais geral, que parte dos supostos à produção de capital e se estende à efetiva produção de mais-valia, ao mais complexo da circulação e concorrência intercapitalista, onde se estabelecem os desvios de preços sobre o valor e as transferências de mais-valia entre capitais de distintas composições técnicas e orgânicas, para dedicar-se à análise de formações sociais inscritas no sistema mundial capitalista, em particular as dependentes. No âmbito mais abstrato da concorrência intercapitalista, em que Marx situa O Capital, para tratar dos determinantes gerais das transferências de valor, Marini também inova ao postular que a mais-valia extraordinária pode atuar não apenas dentro dos ramos produtivos, mas entre ramos distintos, violando os preços de produção. Ele demonstra a compatibilidade do progresso técnico e da mais-valia extraordinária com o pressuposto de equilíbrio dos esquemas de reprodução do Livro II, ao apontar que o progresso técnico economiza força de trabalho e transfere demanda ao setor de bens a de consumo suntuário, articulando o setor I a essa fração do setor II (Cf. Marini, 1979b).

O pensamento de Marini teoriza, portanto, a superexploração do trabalho, avançando criativamente do plano do capital em geral e dos determinantes mais abstratos da concorrência intercapitalista para incluir, na análise, o funcionamento específico de determinadas formações sociais nos marcos do sistema mundial capitalista, patamar analítico que corres- ponde a níveis de abstração que Marx se propôs, mas não pode avançar, como são os do Estado, das relações internacionais de produção e do mercado mundial. Grande parte das críticas que Marini recebeu é oriunda de um marxismo formalista e mecanicista, incapaz de compreender que os conceitos se transformam a partir da necessidade de desdobramento para níveis mais concretos da realidade, ou provêm de um pensamento neodesenvolvimentista, dependentista ou neoliberal que, diante de opção que faz pela subordinação, se preocupa com a crítica radical de Marini aos efeitos econômicos, políticos e sociais do capitalismo dependente. Todavia, se Marini abriu fecundas perspectivas teóricas e analíticas, deixou lacunas que fragilizam sua promissora perspectiva. Diante de certas insuficiências, não cabe à teoria marxista da dependência sacralizar os textos fundadores, mas buscar avançar no vigoroso caminho aberto pelo autor e aprofundar suas formulações.

Uma precisão inicial diz respeito ao próprio conceito de superexploração do trabalho. Se é importante reconhecer, como aponta Jaime Osório, que o conceito não está formulado em O Capital, pois Marx, para elaborar sua teoria da mais-valia, parte do suposto de que os preços da força de trabalho correspondem a seu valor (Cf. Osório, 2004), cumpre destacar que suas raízes teóricas estão claramente delimitadas nessa obra, ainda que não sejam desenvolvidas pelas razões assinaladas. Não se trata, aqui, de sublinhar as referências de Marx no Livro I, em que reconhece a importância histórica da queda dos preços da força de trabalho abaixo de seu valor, apesar de descartá-la para fins analíticos, ou no Livro III, quando a situa como uma importante contratendência ao aumento da composição orgânica do capital e à queda da taxa de lucro. O que importa evidenciar é que, já no Livro I, Marx assinala que a força de trabalho apenas possui valor médio se apresentar intensidade e destreza médias e atuar em condições normais de produtividade. Caso contrário, seu trabalho não apresenta va- 
lor médio e tampouco sua força de trabalho é considerada média, sendo vendida abaixo desse valor. Marx é ainda mais explícito e aponta que a lei geral de valorização do capital só se realiza plenamente quando o capitalista individual emprega diversos trabalhadores, neutralizando suas diferenças, e empregando trabalho social médio:

Se um trabalhador consumisse significativamente mais tempo na produção de uma mercadoria do que o socialmente necessário, se o tempo de trabalho de que ele individualmente necessita se desviasse significativamente do tempo de trabalho socialmente necessário ou tempo de trabalho médio, seu trabalho não seria considerado trabalho médio, tampouco sua força de trabalho como força de trabalho média. Esta não seria vendida, ou o seria apenas abaixo do valor médio da força de trabalho [...] Assim, a lei geral da valorização só se realiza plenamente para o produtor individual quando ele produz como capitalista, emprega muitos trabalhadores simultaneamente e, desse modo, põe em movimento, desde o início, o trabalho social médio (Marx, 2013, p. 495-496).

Portanto, para Marx, a base de sua teoria da mais-valia e das leis gerais da acumulação de capital, fundadas na equivalência entre preços e o valor para grandezas numéricas expressivas, é o valor médio da força de trabalho. Quando se menciona a queda dos preços por debaixo do valor da força de trabalho é ao seu valor médio que se está fazendo referência, caso se tome como parâmetro a teoria marxista. Se uma força de trabalho de destreza e intensidade médias atua por debaixo das condições médias de produtividade, não poderá ser vendida pelo valor da força de trabalho em geral, se lhe atribuindo um preço, pela concorrência, que viola o seu valor de uso.

O valor médio da força de trabalho se define historicamente na economia mundial capitalista, seja de forma análoga ao capital em geral, como síntese das múltiplas particularidades dos preços da força de trabalho, pouco importando a dimensão de sua expressão concreta específica, seja determinando esse valor pelo valor da força de trabalho que atua nas condições médias de produção. Todavia, para calculá-lo em situações monopólicas, que predominam nesse tipo de sistema mundial, deve-se tomar em consideração que as condições médias de produção são estabelecidas pelos capitais de composição superior, os quais produzem a maior parte das mercadorias; que o valor de mercado dos produtos tende a se aproximar do valor individual das mercadorias desse segmento; e que, como contrapartida, os preços da força de trabalho tendem a ser determinados pela grande massa de trabalhadores que a vende abaixo das condições médias, o que desloca os seus preços médios para baixo do valor médio.

A teoria da superexploração do trabalho deve, portanto, tomar como primeiro indicador a queda sistemática dos preços da força de trabalho em relação a seu valor médio na economia mundial. Todavia a superexploração não se caracteriza apenas pela forma aparente, pelos desvios de preços da força de trabalho em relação a seu valor, mas pelo emprego da maior exploração que os determina em função das transferências de valor. Considerando-se que a inscrição de formações sociais na economia mundial capitalista é mediada por classes dominantes que dirigem o Estado nacional e estabelecem espaços de circulação e produção de mercadorias com autonomia relativa, podemos afirmar que a superexploração do trabalho ocorre de forma estrutural, tipicamente, quando esses processos de acumulação estão determinados, interna e externamente, por situações monopólicas que inserem a maior parte de sua força de trabalho significativamente por baixo das condições médias de produtividade do capital, em âmbito nacional e internacional, mais a afastando delas do que aproximando-as. Face à queda das taxas de mais-valia que lhes são impostas, os capitais de composição média e inferior recorreriam à maior exploração do trabalhador. Define-se, assim, um segundo indicador para o fenômeno: a queda de preços da força de trabalho frente aos estabelecidos pelas condições médias de produção em âmbito nacional.

Essas observações são importantes para 
assinalar que, ao contrário do que imaginam autores como Jorge Castañeda, Enrique Hett e José Valenzuela Feijoó, os preços da força de trabalho, nos países dependentes, não podem ser tomados como equivalentes aos seus valores, por estarem determinados pela luta de classes, descartando-se as flutuações de conjuntura. Tampouco representam os valores histórico-morais de nossos trabalhadores, limitados por razões internas, como quer Claudio Katz. Essas postulações derivam de um nacionalismo metodológico que incorre em dois erros: concebe a produtividade em termos nacionais, desarticulando-a das transferências de valor que incidem sobre as economias dependentes e no seu interior, afetando, particularmente, a grande massa de trabalhadores; ${ }^{8}$ além disso, manejam um conceito equivocado de valor da força de trabalho que não toma em consideração o valor social médio da força de trabalho na economia mundial capitalista.

No caso de Cardoso e Serra, o obscurecimento se faz ainda mais profundo, porque se trata, como vimos, não apenas de ignorar o valor médio da força de trabalho na economia mundial, mas de negá-lo sob a afirmação de que o conceito de trabalho socialmente necessário não possuiria operacionalidade na economia mundial, em função da escassa mobilidade internacional da força de trabalho (Cf. 亏ें Cardoso; Serra, 1978). Como assinala corretađ̇ mente Marini, em réplica, a mobilidade inter-

${ }^{8}$ Brasil, México e Argentina possuíam, em relação aos Es-

$\vec{\sim}$ tados Unidos, quanto à renda per capita (PPP), anos de

ธิ escolaridade e jornada de trabalho (JT), em 2015: o Brasil

T. tinha 59\% da escolaridade dos Estados Unidos, 27,5\% da

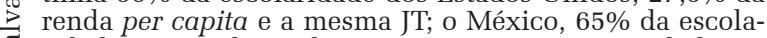

ridade, $33,5 \%$ da renda per capita, e $27 \%$ a mais de horas

trabalhadas; e a Argentina 75\% da escolaridade e 36\% da

renda per capita, sem diferenças de JT (Cf. PNUD, 2018; The Conference Board, 2018).

${ }^{9}$ Marini assinala que a chave para as transferências de mais-valia e para os diferenciais de salário na economia mundial capitalista são as assimetrias de produtividade, oriundas dos
Se essa crítica pode ser feita aos opositores do pensamento de Marini, é preciso reconhecer que, embora esse autor tenha demonstrado corretamente que as transferências de valor impostas aos países dependentes lhes determinam uma forma especifica de exploração - pautada na queda dos preços da força de trabalho abaixo de seu valor -, não se desvencilhou inteiramente do nacionalismo metodológico. Ao utilizar o conceito de valor da força trabalho, embora não explicite, parece fazê-lo exclusivamente em bases nacionais, desarticulando-o de seu eixo de referência mundial, entrando em contradição com seu ponto de partida analítico, vale dizer, a inscrição das formações sociais dependentes nos processos de acumulação da economia mundial capitalista. Dessa forma, desvincula a queda dos preços da força de trabalho do seu valor médio mundial, que pode se expressar em uma massa superior de bens de consumo necessários, com a sua desvalorização, associada ao aumento da capacidade produtiva nos países centrais.

Esta confusão conceitual inclinou Marini a afirmar que a mais-valia relativa, tal como definida por Marx, seria incompatível com a superexploração do trabalho. Embora seus trabalhos não sejam totalmente conclusivos em relação a isso, essa visão parece predominar. Em sua resposta a Cardoso e Serra, coloca muita ênfase no fato de que a dinamização do setor de bens de consumo necessários se associaria à expansão do comércio exterior. Assim, ele aponta que a superexploração inclui uma modalidade de mais-valia relativa, vinculada ao aumento da intensidade do trabalho, que, ao se generalizar, afetaria os dois tempos da força de trabalho. "Señalemos, inicialmente, que el concepto de superexplotación no es idéntico al de plusvalía absoluta, ya que incluye también una modalidad de plusvalía relativa - la que corresponde al aumento de la intensidad del trabajo" (Marini, 1973, p. 92).

Todavia não fica explicitado por Marini

monopólios tecnológicos, e não a restrita circulação internacional de força de trabalho, como querem autores como Claudio Katz (Cf. Amin, 1993; Katz, 2018). 
em que nível de análise está situando sua abordagem quando descreve a intensidade do trabalho como a mais-valia relativa específica da superexploração: se está se referindo aos mecanismos pelos quais funciona uma tipologia pura, a superexploração do trabalho, ou se está analisando diretamente a realidade concreta.

Em outras passagens, parece apontar para caminho metodológico distinto, quando menciona que, nos países dependentes, a superexploração obstaculiza o trânsito da mais-valia relativa como forma predominante das relações entre capital e trabalho, abrindo espaço para incorporar sua presença de forma subordinada ao protagonismo da maior exploração do trabalhador.

La tarea fundamental de la teoría marxista de la dependencia consiste en determinar la legalidad específica por la que se rige la economía dependiente [...] Como quiera que sea, la exigencia de especificar las leyes generales del desarrollo capitalista no permite, desde un punto de vista rigurosamente científico, recurrir a generalidades como la de que la nueva forma de la dependencia reposa en la plusvalía relativa y el aumento de la productividad. Y no lo permite porque ésta es la característica general de todo desarrollo capitalista, como se ha visto. El problema está pues en determinar el carácter que asume en la economía dependiente la producción de plusvalía relativa y el aumento de la productividad del trabajo.

En este sentido, se pueden encontrar en mi ensayo indicaciones que, aunque notoriamente insuficientes, permiten vislumbrar el problema de fondo que la teoría marxista de la dependencia está urgida a enfrentar: el hecho de que las condiciones creadas por la superexplotación del trabajo en la economía capitalista dependiente tienden a obstaculizar su tránsito desde la producción de plusvalía absoluta a la de plusvalía relativa, en tanto que forma dominante en las relaciones entre el capital y el trabajo. La gravitación desproporcionada que asume en el sistema dependiente la plusvalía extraordinaria es un resultado de esto y corresponde a la expansión del ejército industrial de reserva y al estrangulamiento relativo de la capacidad de realización de la producción (Marini, 1973, p. 99-100, grifo nosso).

Entretanto, o autor não desenvolve posteriormente essa indicação metodológica pro- missora. Embora a centralidade da superexploração do trabalho fosse corretamente apontada por Marini, sua compatibilidade ou não com a mais-valia relativa não pode ser determinada em níveis teóricos mais abstratos, mas em sua articulação com a análise concreta dos padrões de acumulação de capital. A tentativa de determinar essa incompatibilidade - ressalvado o caso polêmico da intensidade do trabalho ${ }^{10}$ -, em níveis abstratos, que se imporia sobre os padrões concretos específicos de acumulação, fragilizou, desnecessariamente, o importante aporte de Marini, cujos desdobramentos teóricos, no plano econômico, social e político alta concentração de capitais, altos níveis de desigualdade, baixos salários dos trabalhadores, fortes restrições ao mercado interno, subimperialismo e busca do socialismo como alternativa à dependência -, prescindem dessa hipótese tão restritiva. Essa incompatibilidade sugerida não foi demonstrada nem empiricamente, nem formalmente por Marini, o que colocou seu aporte sob ataques que lhe objetavam haver expansão do consumo das classes trabalhadoras já com o desenvolvimento da produção agroexportadora, em determinados países da América Latina, ${ }^{11}$ e ser a mais-valia relativa a especificidade do desenvolvimento do capitalismo a partir da grande indústria, pontos de convergência da crítica de Cardoso $(1975,1979,1993,2010)$, Cardoso e Serra (1978), Palma (1978) e, inicialmente, Cueva (1974).

Entretanto essas críticas possuem forte

${ }^{10}$ Marcelo Carcanholo (2017) tem razão em questionar a intensidade do trabalho como forma de mais-valia relativa. A hipótese de Marini de que o aumento da intensidade de trabalho ao se generalizar, sem a remuneração equivalente, cria um novo eixo de valor da força de trabalho, afetando os dois tempos da jornada de trabalho, entra em contradição com a tese inerente à superexploração de que os preços da força de trabalho estão sistematicamente abaixo do valor.

${ }^{11}$ Argentina e Uruguai se tornaram os países com maior consumo per capita de carne bovina do mundo na primeira metade do século XX. O consumo per capita anual de carne na Argentina saltou de 56,1 kg, nos anos 1914-19, para $87,9 \mathrm{~kg}$, nos anos 1950-59. Entre 1914-19, as exportações superavam o consumo interno, com 590.000 toneladas exportadas e 460.000 consumidas internamente; mas, a partir dos anos 1920, o consumo interno se tornou o eixo dinâmico (Cf. Guadagni, 1964). 
teor desenvolvimentista, lançam mão de uma interpretação mecanicista e equivocada da obra de Marx e pecam no essencial: negligenciam o fenômeno da superexploração e os fortes limites que coloca à expansão da mais-valia relativa. Postular a possibilidade de coexistência da mais-valia relativa com a centralidade da superexploração do trabalho não significa atribuir-lhe caráter progressivo e pertinência às etapas mais avançadas do capitalismo dependente. Junto ao fenômeno do desenvolvimento da produtividade e da elevação da composição técnica e orgânica do capital, crescem também sua concentração e centralização, assim como as transferências de mais-valia intercapitalistas. Mesmo no Tomo I de O Capital, dedicado ao capital em geral, Marx deixou importantes indicações sobre tais desdobramentos, colocando em cheque as interpretações que fazem da mais-valia relativa o futuro do capitalismo baseado no progresso técnico. Essas observações estão alinhadas também a determinadas formulações feitas por Marx e Engels em $O$ Manifesto do Partido Comunista.

No Capítulo XXIV do Tomo I de $\mathrm{O} C \mathrm{Ca}$ pital, Marx menciona que a etapa que sucede à acumulação primitiva e à pré-história do capital se desenvolve por meio do jogo das leis imanentes da própria produção capitalista, onde crescem, de maneira correlata, em escala cada vez maior, a forma cooperativa do processo de trabalho, a aplicação técnica e consciente da ciência, a exploração planejada da terra, o entrelaçamento de todos os povos na rede do mercado mundial, o caráter internacional do regime capitalista, mas também a concentra+ ção e a centralização do capital. Assim, aponta:

Com a diminuição constante do número de magnatas do capital, que usurpam e monopolizam todas as vantagens desse processo de transformação, aumenta a massa da miséria, da opressão, da servidão, da degeneração, da exploração, mas também a revolta da classe trabalhadora, que, cada vez mais numerosa, é instruída, unida e organizada pelo próprio mecanismo do processo de produção capitalista (Marx, 2013, p. 832).
Da mesma forma, em $O$ Manifesto do Partido Comunista, Marx e Engels assinalam:

Até aqui todas as sociedades repousaram, como vimos, no antagonismo entre classes opressoras e oprimidas. Mas, para se oprimir uma classe, é necessário assegurar-lhe condições para que possa, no mínimo, prolongar sua existência servil. Sob o regime da servidão, o servo chegou a membro da comuna, tal como sob o jugo do absolutismo feudal, o pequeno burguês chegou a burguês. Por sua vez, o operário moderno, em vez de elevar-se com o progresso da indústria, decai cada vez mais, abaixo das condições de sua própria classe. O operário transforma-se em indigente, e a miséria cresce mais rápido do que a população e a riqueza. Evidencia-se assim, claramente, que a burguesia é incapaz de permanecer por mais tempo como classe dominante da sociedade e de impor-lhe, como lei e como regra, as condições de vida de sua classe (Marx; Engels, 2001, p. 44).

As contradições entre a superexploração do trabalho e a mais-valia relativa avançam à medida que se desenvolvem a composição orgânica do capital, o monopólio tecnológico, o peso do setor de bens de consumo suntuários, a centralização do capital e a financeirização no processo de acumulação, podendo, no limite, levar ao bloqueio dessa forma de mais-valia e à regressão salarial de amplos contingentes de trabalhadores. Assim, a título de demonstração algébrica, podemos apontar três situações: a primeira, referente a um capital determinado antes de sofrer transferências de mais-valia; a segunda, em que esse capital passa a sofrer transferências de mais-valia que incidem no setor de bens de consumo suntuário a partir de variações da produtividade; e a terceira, em que um capital de composição inicial idêntica, que atua no setor de bens de consumo necessário, também passa a sofrer transferências de mais-valia pelo mesmo motivo:
1) $c+v+m=p$
2) $\mathrm{C}+\frac{v}{x}+\mathrm{m}=\frac{p \cdot y}{z}$
3) $\mathrm{C}+\frac{v}{x}+\mathrm{m}=\frac{p \cdot y}{x}$ 
Sabe- se que $c=$ capital constante, $V=$ capital variável e $x=$ desvalorização das mercadorias que representam os bens de consumo necessário, a qual é superior à variação de sua produtividade, implicando a queda do preço abaixo do valor; $m=$ mais-valia, $p=$ valor do produto, $y=$ variação da produtividade do capital de composição técnica inferior e $z=$ desvalorização média das mercadorias no setor de bens de consumo suntuários, que é inferior à variação de sua produtividade, implicando elevação do preço acima do valor. Por questões de simplificação, supomos que cada mercadoria do setor de bens de consumo necessário representa a média daquelas que o compõem quanto ao valor e à produtividade; tal suposição é extensiva às mercadorias do setor de bens de consumo suntuário.

Na primeira equação, se supusermos c $=200, v=300, m=500$ e $p=1000$ e, na segunda, $x=2, y=1,4$ e $z=2$, veremos que a apropriação de mais-valia sofrida pelo capital de composição inferior neutraliza a elevação de sua taxa de mais-valia e mantém inalterada a taxa de lucro, bloqueando-lhe a mais-valia relativa e o aumento dos salários. Assim, a taxa de lucro de um determinado capital igual a 1 , na equação 1 , se reproduz na equação 2 , havendo queda do valor das mercadorias que representam os bens de consumo necessário e suntuário idêntica à da massa nominal de salários. Mas, se, para elevar a produtividade, esse capital aumentou sua composição orgânica, a restituição de sua taxa de lucro exigiria corte de salários reais, aumento da jornada ou da intensidade de trabalho. Se alterarmos os valores de z, aumentando-os, e reduzindo os de y, novamente a taxa de lucro cai. Igualmente, a taxa de lucro cairá se partirmos de uma de taxa de mais-valia maior na composição original do capital tecnicamente inferior, mantendo-se as variações de produtividade inicialmente indicadas.

Na terceira equação, se supusermos $X=$ 2 e $y=1,3$, a taxa de lucro cairá para o capital de composição inferior em relação à equação 1 - de 1 para 0,85-, impedindo que ele desfrute de mais-valia relativa e elevação de salários. Para restabelecê-la, total ou parcialmente, terá de utilizar a maior exploração do trabalhador e, eventualmente, reorientar a produção para os bens de consumo suntuários. As mesmas correlações anteriores se aplicam aqui: a subida de $y$ e a queda de $x$ favorecem a mais-valia relativa para o capital de composição inferior, o aumento da composição orgânica desfavorece, o aumento da taxa de mais-valia na equação 1 , mantidas as variações de produtividade inicialmente indicadas, desfavorece na equação 3 .

Essas equações elementares demonstram que a heterogeneidade tecnológica e a atuação da mais-valia extraordinária, dentro e entre os ramos ou setores produtivos, podem levar ao bloqueio da mais-valia relativa nos capitais de composição tecnicamente inferior, mesmo na vigência da elevação de sua produtividade. Se esses capitais empregarem a maior parte da força de trabalho de uma formação social, estará instituída uma situação de prevalência da superexploração do trabalho que restringirá ou abolirá a mais-valia relativa, como resultado das transferências de valor que sofrem. Mas, se os exercícios algébricos indicam essas possibilidades, serão as análises históricas dos padrões de acumulação que permitirão deslindar as formas em que se apresenta a superexploração nos países dependentes. Nessas análises retrospectivas e prospectivas, há de se integrar, entre as variáveis da superexploração, o aumento do valor da força de trabalho sem a elevação correlata dos seus preços, o que constitui uma forma disfarçada de queda de preços por baixo do seu valor, compatível, entretanto, com o aumento real de salários.

A extensão da superexploração aos países centrais proposta por Marini encontra articulação com o próprio pensamento de Marx e de Engels referente aos efeitos das etapas avançadas da concentração e centralização de capitais sobre os trabalhadores. Essa extensão não elimina a especificidade dos países dependentes na divisão internacional do trabalho, como apontam alguns teóricos identificados com a 
teoria marxista da dependência, mas introduz um novo patamar na composição técnica dos monopólios, o qual situa a maior parte da força de trabalho dos países centrais por baixo das condições sociais médias de produção mundial. O aumento vertiginoso dos índices de desigualdade, nos Estados Unidos e na Europa Ocidental, e a estagnação dos salários, demonstrados pelos estudos de Piketty (Cf. Piketty, 2014), constituem expressão dessa tendência.

O alto nível de centralização e concentração de capital se expressa nos impactos cada vez mais medíocres dos ciclos de ingresso de capital estrangeiro para o desenvolvimento do capitalismo dependente. Os estudos sobre esses ciclos, realizados pela teoria marxista da dependência, destacam a tendência à descapitalização no médio e longo prazo, intermediada por períodos de predomínio de ingressos que concentram e centralizam o capital (Cf. Caputo; Pizarro, 1974; Martins, 2011; Santos 1978a). $\mathrm{O}$ resultado tende a ser o aumento estrutural dos estoques de capital estrangeiro em relação ao PIB e das transferências, o que se combina com a volatilidade dos fluxos de entrada, pressionando, na longa duração, em favor da expansão dos saldos comerciais, via superexploração do trabalho, salvo situação específica de forte ingresso de divisas com turismo ou emigrantes. Se Fernando Henrique Cardoso (1993) destacou que sua ênfase nos estudos sobre capitalismo periférico está no desenvolvimento, e não na dependência, apostando que suas necessidades de expansão seriam financiadas pelas corporações transacionais e por organismos internacionais, expressando processos históri-

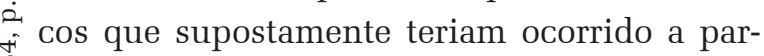
$\infty$ ríodo do boom das commodities, entre 2004 e 2013, a partir dos anos 1980, a América Latina cresceu abaixo das taxas de crescimento per capita da economia mundial e se afastou dos níveis de renda per capita do núcleo orgânico da economia mundial. ${ }^{12}$

O padrão neoliberal, ao elevar dramaticamente os estoques relativos de capital estrangeiro na América Latina, aumentou muito mais as remessas do que as entradas de capital, tornando negativos os fluxos líquidos internacionais de capital, mesmo durante os períodos de crescimento dos ingressos. Tal situação exigiu uma balança comercial fortemente positiva, inclusive no período de apreciação cambial, o que só foi possível com a forte alta dos preços das commodities, que se iniciou em 2004 e abriu o espaço para um reformismo moderado na região, implementado pelos governos de centro-esquerda, ou mais radicais, sob forte mobilização nacional-popular e orientação latino-americanista. ${ }^{13}$

A queda dos preços das commodities e as reversões do ciclo de ingressos de capitais estrangeiros tornaram-se o ponto de partida para um novo período de inflexão na história latino-americana, quando as forças neoliberais, suas variações fascistas e o imperialismo tomam o protagonismo na região, aproveitando-se das debilidades da centro-esquerda e da desarticulação interna do bloco histórico que emergiu a partir da primeira década do século XXI. O provável esgotamento, no final desta década, do ciclo de Kondratiev expansivo, iniciado em 1994, a perda intensa de velocidade

${ }^{12}$ Se compararmos os níveis de renda per capita de Brasil Argentina e México, em relação aos Estados Unidos, teremos os seguintes resultados: Brasil-E.U.A: 1950: 25,5\%; 1980: 39,9\%; 2003: 24,8\% 2013: 30\%; 2017: 25,7\%; Argentina -E.U.A: 1950: 61,7\%; 1980: 52,2\%; 2003; 28,7\%; 2013 : 37,5\%; 2017: 34,2\%; e México-E.U.A: 1950: 35\%; 1980: 48,9\%; 2003: 32,6\%; 2013: 33,9\%; 2017: 33,5\%. Cálculos do autor (Cf. The Conference Board, 2018).

${ }^{13}$ Entre 1992 e 1998, período cíclico de boom de ingressos de capital estrangeiro, eles superaram as saídas sob a forma de remessas de lucros, juros e outros serviços em U\$ 27 bilhões, ao passo que a balança comercial foi negativa em U\$ 89 bilhões. Entre 2010 e 2014, novo período de boom de ingressos de capital estrangeiro, as saídas os superaram em U\$ 34 bilhões, e a balança comercial foi positiva em U\$ 136 bilhões (Cf. Cepalstat, 2018). 
de expansão dos fluxos internacionais de capital e do comércio exterior, o aumento do patamar estrutural de remessas com a elevação dos estoques de investimento direto e o avanço dos processos de concentração e centralização de capitais fazem prever um forte aumento das taxas de superexploração no capitalismo dependente latino-americano, restringindo, cada vez mais, as possibilidades da mais-valia relativa.

Entre as formas que impulsionam a superexploração no capitalismo contemporâneo está a financeirização do capital, produtora de capital fictício, respaldado essencialmente pelo Estado, em particular pela expansão da dívida pública. $\mathrm{O}$ impacto que assume a produção de capital fictício no capitalismo contemporâneo tem forte relação com a revolução científico-técnica e a automação que, ao reduzirem significativamente a massa de valor representada pela força de trabalho, tornam cada vez mais medíocres os incrementos na taxa de mais-valia e a economia de força de trabalho para sustentar a mais-valia extraordinária. Busca-se resolver a contradição entre o aumento da produtividade e a produção de valor para a acumulação de capital. Essa hipótese tem sido sustentada nos trabalhos de Adrián Sotelo Valencia (2010) e Carlos Eduardo Martins (2011). A geração de capital fictício, cuja fórmula básica é D-D , traz consigo a expectativa de produzir mais-valia sem a mediação do trabalho e, para realizar-se, subtrai demanda e valor aos segmentos produtores de bens de consumo necessários, transferindo-os ao setor de bens de consumo suntuários.

Marini não se debruçou suficientemente sobre o tema da financeirização e suas implicações sobre o subimperialismo, embora o tenha destacado em sua análise da crise do desenvolvimento associado, quando sublinha as vinculações entre a dívida interna e a dívida externa. O autor aponta, entretanto, em textos como La politica de fomento a las exportaciones y el déficit publico en Brasil (1988) e El experimento neoliberal en Brasil (1992), a presença de uma economia da transferência que impossibilitava à economia brasileira funcionar efetivamente como uma economia exportadora. Essa economia da transferência atuava a partir de dois grandes mecanismos: a) regulações protecionistas da substituição de importações, que garantiam a reserva de mercado e preços monopólicos à burguesia industrial interna, estrangeira ou associada; e b) formação de uma grande dívida pública interna, originalmente para envio de dólares aos pagamentos de juros da dívida externa, que tornou-se parte substantiva do processo de acumulação da burguesia local, internacionalizando-se a partir da abertura financeira promovida pelo Governo de Fernando Henrique Cardoso, mantida nos governos petistas.

Essa economia da transferência limitou significativamente o alcance do projeto subimperialista brasileiro ao reduzir as taxas de investimento e criar, no Estado, uma fonte de acumulação e realização de capital fictício, que substituiu parcialmente a produção e realização de mercadorias. O desmonte do regime de acumulação vinculado à dependência industrial, pela abertura comercial e financeira dos anos 1990, aprofundou ainda mais essa limitação, ao sobrevalorizar a moeda, desindustrializar, desincentivar as exportações e tornar a produção de capital fictício, via expansão da dívida pública, o componente central da economia de transferência.

Durante os governos petistas, a retomada da política industrial via Banco Nacional de Desenvolvimento Econômico e Social (BNDES) reativou o projeto subimperialista, atribuindo-lhe novo caráter em relação ao dos anos 1970 e 1980, quando se vinculou à pretensão de internalizar a indústria pesada e o controle das tecnologias nuclear e eletrônica por meio da dependência financeira, à superexploração, ao terrorismo de Estado e à imposição de fronteiras regionais ideológicas, idealizadas por Golbery do Couto e Silva, o mais destacado teórico da ditadura militar do grande capital no Brasil. Nos governos petistas, buscou-se alavancar setores industriais muito mais específicos, sem a 
mesma importância estratégica nas cadeias de valor globais, vinculados à agroindústria, recursos minerais e construção civil, impulsionando sua internacionalização a partir da formação de grandes monopólios produtivos internos.

Este subimperialismo projetou-se comercial e financeiramente, principalmente sobre a América do Sul, com quem auferiu expressivos superávits comerciais, mas também sobre o Caribe e a África, obtendo significativas remessas de lucros, geradas a partir de investimentos no exterior. Vinculou-se a uma política internacional centrista e multilateral, de afastamento relativo dos Estados Unidos, aproximação da China por meio do BRICS, e do integracionismo bolivariano, sem adotar o seu anti-imperialismo. No plano interno, o centrismo manifestou-se em uma política moderada de avanços sociais e democráticos, que pretendeu se agregar ao padrão neoliberal, fortalecendo a fração industrial da burguesia, sua base nacional e o controle estatal dos recursos naturais, reajustando a hegemonia do capital financeiro fictício e do capital estrangeiro, mas sem ameaçá-la. O golpe de 2016 desarticulou esse projeto em favor de um padrão neoliberal muito mais puro: alinhado aos Estados Unidos, baseado em altas taxas de superexploração, no protagonismo do capital financeiro fictício e $\infty$ na alienação ao capital estrangeiro do controle : nacional sobre recursos estratégicos e cadeias Фั de valor agregado importantes.

O subimperialismo brasileiro apresenta, assim, duas possibilidades: como forma de realização do excedente econômico e de investimentos em função das limitações do mercado interno i सं grau de autonomia na dependência e se articulam com distintas forças sociais, podendo apresentar-se sob várias formas históricas.

Como projeto geopolítico, o subimperialismo foi duplamente derrotado: pelo isolamento dos governos militares e o desmonte de seu projeto de autonomia tecnológica na de- pendência em favor do neoliberal; e pelo golpe de 2016, que bloqueou e destruiu a lenta reativação do capitalismo de Estado para impulsionar políticas industriais e elevar o controle nacional sobre recursos estratégicos. Como forma de realização dos excedentes e de investimentos, o subimperialismo foi limitado pela financeirização do Estado no Brasil, pela destruição parcial de sua base industrial e pela expansão do mercado interno proporcionada pelo boom das commodities. A economia política do golpe, todavia, impõe a retração do consumo popular e o corte drástico de gastos públicos primários, vinculando o dinamismo econômico às exportações e aprofundando o grau de transnacionalização da economia brasileira, devendo implicar a reorientação para a conquista agressiva de mercados internacionais.

A tentativa de conter o protagonismo do capital financeiro, reduzindo as taxas de juros, e combinando-a a uma política fiscal fortemente restritiva, indica que esse movimento de reorientação tende a se articular aos setores de menor complexidade tecnológica e a ser dirigido pelo capital internacional, desvinculando-se, cada vez mais, da associação entre capitalismo de Estado e frações burguesas industriais locais. Seus limites estão na associação a segmentos de baixo valor agregado e na ausência de um sistema nacional de inovação capaz de projetá-lo para etapas superiores da divisão internacional do trabalho.

Finalmente, em relação ao tema do socialismo, nem Ruy Mauro Marini, nem Theotonio dos Santos ou Vânia Bambirra sustentaram essa opção política com base na estagnação econômica que Fernando Henrique Cardoso, José Serra, Bresser Pereira, Guido Mantega e Gabriel Palma, entre outros, lhes atribuíram. Para eles, o socialismo era a opção para enfrentar a superexploração, os altos níveis de desigualdade, a desnacionalização, as violações à democracia e os limites crescentes que a dependência coloca ao desenvolvimento no capitalismo periférico, condenando-o a novas formas de subdesenvolvimento. O socialismo, 
embora partisse de revoluções nacionais, não deveria se restringir a esse espaço, nem buscar o delinking como um modelo independente de condições históricas específicas e provisórias, mas sim articular um novo eixo geopolítico de poder regional e intercontinental na economia mundial, estabelecendo guerras de posição e de movimento de curto, médio e longo prazo com o imperialismo e seus sócios periféricos, capazes de abrir brechas na divisão do mundo entre centro e periferia e impulsionar a construção de outra ordem mundial.

Recebido para publicação em 31 de março de 2018 Aceito em 13 de maio de 2018

\section{REFERÊNCIAS}

AMIN, S. Autobiografia intelectual. Rafaela: H. Garetto Editor, 1993. 240p.

BAMBIRRA, V.El capitalismo dependientelatinoamericano. México: Siglo XXI, 1974. 180 p.

Teoría de la dependencia: una anticrítica. México:

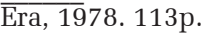

CAPUTO, O.; PIZARRO, R. Dependencia y relaciones internacionales. Costa Rica: Educa, 1974. 281p.

CARCANHOLO, M. Dependencia, superexplotación deltrabajo y crisis: una interpretación desde Marx. Madri Maia, 2017. 179p.

CARDOSO, F. H. Autoritarismo e burocratização. São Paulo: Difel, 1975. 240p.

O modelo político brasileiro e outros ensaios. São Paulo: Difel, 1979. 211p.

. As ideias e seu lugar. Petrópolis: Vozes, 1993. 244p.

Xadrez internacional \& social-democracia. Lisboa: Dom Quixote, 2010. 261p.

; FALETTO, E. Dependência e desenvolvimento na América Latina: ensaio de interpretação sociológica. Petrópolis: Vozes, 1984. 143p.

; SERRA, J. Las desventuras de la dialéctica de la dependencia. Revista mexicana de Sociología, México, v. 40, p. 9-55, 1978. Número extraordinario.

CASTAÑEDA, J.; HETT, E. El economismo dependentista. México: Siglo XXI, 1978. 191p.

CEPALSTAT. Comisión económica para América Latina y el Caribe. Bases de datos y publicaciones estadísticas. 2018-. Disponível em: <http://estadisticas.cepal.org/ cepalstat/Portada.html>. Acesso em: 10 fev. 2018.

CUEVA, A. Problemas y perspectivas de la teoría de la dependencia. Historia y sociedadda, p. 55-77, 1974.

Las democracias restringidas de America Latina. Quito: Planeta, 1989.147p.

FEIJOÓ, J. V. Sobreexplotación y dependencia. Investigación económica, México, v. 57, n. 221, p. 105-127, jul./sept. 1997.
GOLDENSTEIN, L. Repensando a dependência. São Paulo: Paz e Terra. 1994. 173p.

GUADANI, A. Estudio econométrico del consumo de carne vacuna en Argentina en el período 1914-1959. Desarrollo económico, Buenos Aires, v. 3, n. 4, p. 517-533, jan./marzo. 1964.

GUNDER FRANK, A. América Latina: subdesarrollo o revolución. México: Era, 1973. 353p.

KATZ, C. Controversias sobre lasuperexplotación. Viento sur, marzo 2018. Disponível em: < http://vientosur.info/ spip.php?article13568>. Acesso em: 10 fev. 2018.

KAY, C. Latin American theories of development and underdevelopment. Londres: Routledge, 1989. 295p.

MANTEGA, G. A economía política brasileira. Petrópolis: Vozes, 1984. 288p.

MARINI, R. M. La acumulación capitalista dependiente y lasuperexplotacióndeltrabajo. In: RUY Mauro Marini Escritos. 1972. Disponível em: <http://www.mariniescritos.unam.mx/043_acumulacion_superexplotacion. html>. Acesso em: 25 fev. 2018.

$101 \mathrm{p}$

Dialéctica de la dependencia. México: Era, 1973.

Subdesarrollo y revolución. 5. ed. México: Siglo $\overline{\mathrm{XXI}}$, 1974. 204p.

La acumulación capitalista mundial y el subimperialismo. Cuadernos políticos, México, n. 12, p. 20-39, abr./jun., 1977a. Ediciones era.

Estado y crisis en Brasil. Cuadernos políticos, México, n. 13, p. 76-84. jul./sept. 1977b. Ediciones era.

Las razones del neodesarrollismo: respuesta a $\mathrm{F}$ H. Cardoso y J. Serra. Revista Mexicana de Sociología, México, n. 40, p 57-106, 1978. Número extraordinario.

El ciclo del capital en la economía dependiente. In: OSWALD, Ú. (Org.). Mercado y dependencia. México: Nueva Imagen, 1979a. p. 37-55.

Plusvalía extraordinaria y acumulación de capital. Cuadernos políticos, México, n. 20, p. 18-39, abr.jun. 1979b. Ediciones era.

Promoção às exportações e déficit público. Brasília: UNB: CNPq, 1988.

El experimento neoliberal en Brasil. In: RUY Mauro Marini escritos, 1992. Disponível em: <http://www. marini-escritos.unam.mx/072 experimento neoliberal brasil.html>. Acesso em: 5 fev. 2018.

Procesos y tendencias de la globalización capitalista. In:__ _ MILLÁN, M. (Org.). La teoría social latinoamericana: cuestiones contemporáneas. México: UNAM, 1994. t 4., p. 49-68.

MARTINS, C. E. Pensamento social. In: MARTINS, C. E. et al. (Org.). Latinoamericana: enciclopédia contemporânea de América Latina e Caribe. São Paulo: Boitempo, 2006. p. 925-934

Globalização, dependência e neoliberalismo na América Latina. São Paulo: Boitempo, 2011. 367p.

Algumas reflexões em torno do conceito de superexploração do trabalho. Revista da sociedade brasileira de economia política, n. 48, p. 28-43, set./dez. 2017.

MARX, K. O capital: livro I. São Paulo: Boitempo Editorial, 2013. 894p

O capital: livro I. São Paulo: Boitempo Editorial, 2017. $980 \mathrm{p}$

- ENGELS, F. O manifesto do partido comunista. Porto Alegre: L\&PM Pocket, 2001. 131p. 
OSÓRIO, J. Crítica de la economía vulgar: reproducción delcapital y dependência. México: Miguel Ángel Porrua, 2004. (Coleção América Latina e Nova ordem mundial).

. Sobre dialéctica, superexplotación y dependencia: notas acerca de Dialéctica de la dependencia. Argumentos, México, n. 72, p. 57-73, mayo/agosto, 2013.

PALMA, G. Dependency: a formal theory of underdevelopment or a methodology for the analysis of concrete situations of underdevelopment. World development, Londres, v. 6, p. 881-924, 1978.

PEREIRA, L. C. B. Seis interpretações sobre o Brasil. Dados: revista de Ciências sociais, Rio de Janeiro, v. 25, n. 3, p. 269-306, 1982.

PIKETTY, T. Capital in the twenty-fisrt century. Cambridge: Harvard University Press, 2014. 685p.

PNUD. Human Development Index (HDI). [20--]. Disponível em: <http://hdr.undp.org/en/content/humandevelopment-index-hdi>. Acesso em: 5 fev. 2018.
A TEORIA MARXISTA DA DEPENDÊNCIA À LUZ DE MARX ...

POLANCO, H.-D. Comentarios a el ciclo del capital enla economia dependente In: OSWALD, Ú. (Org.). Mercado y dependencia. México: Nueva imagen, 1979. p. 57-61.

SANTOS, T. Imperialismo y dependencia. México: Era, 1978a. 491p.

Socialismo o fascismo: el nuevo carácter de la dependencia y el dilema latinoamericano. México: Edicol, 1978b. 341p.

. A teoria da dependência: balanço e perspectivas. Río de Janeiro: Civilização Brasileira, 2000. p. 176.

THE CONFERENCE BOARD. Total Economy Database. mar. 2018. Disponível em: <https://www.conferenceboard.org/data/economydatabase/>. Acesso em: 30 mar. 2018.

VALENCIA, A. S. Crisis capitalista y desmedida del valor: un enfoque desde los Grundrissse. Mexico: Itaca, 2010. $143 \mathrm{p}$.

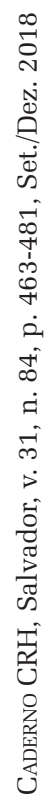

480 


\section{THE DEPENDENCY THEORY IN THE LIGHT OF MARX AND CONTEMPORARY CAPITALISM}

\section{Carlos Eduardo Martins}

The article analyzes the main contributions of the political economy of dependence from the debates that the work of Ruy Mauro Marini aroused. It proposes the theoretical reformulation of the concepts of superexploitation of labor and of subimperialism with the aim of updating and enriching the Marxist theory of dependency to analyze the trends of contemporary capitalism and the historical forms it has assumed in Latin America. It is divided into three parts, the first where Marini's thinking and his contributions to political economy are presented, the second where the main criticisms of his approach are presented, and the third one where we sustain his approach from some reformulations that are considered necessary to develop it.

KEY WORDS: Superexplotation of labour. Subimperialism. Marxist political economy. Marini. Marx.
LA THÉORIE DE LA DÉPENDENCE À LA LUMIÈRE DU MARX ET DU CAPITALISME CONTEMPORAINE

\author{
Carlos Eduardo Martins
}

L'articleanalyse les principales contributions de l'économiepolitique de la dépendance aux débats suscités par le travail de Ruy Mauro Marini. Il propose la reformulation théorique des concepts de surexploitation du travail et de sub-impérialisme dans le but de mettre à jour et d'enrichir la théorie marxiste de la dépendance pour analyser les tendances du capitalismecontemporain et les formes historiques qu'il a assumées en Amérique Latine. Il est divisé en trois parties, la première où la pensée de Marini et ses contributions à l'économie politique sont présentées, la seconde où les principales critiques de son approche sont présentées, et la troisième où il cherche à soutenir son approche à partir de certaines reformulations qui sont considérés comme nécessaires pour le développer.

Mots CLÉs: Superexploration du travail. Sousimperialism. Économiepolitiquemarxiste. Marini. Marx.

Carlos Eduardo Martins - Doutor em Sociologia. Professor Associado do Instituto de Relações Internacionais e Defesa (IRID) e do Programa de Economia Política Internacional da UFRJ (PEPI). Coordenador do Laboratório de Estudos sobre Hegemonia e Contra hegemonia da UFRJ (LEHC). Pesquisador dos grupos de trabalho sobre Estados Unidos e sobre Integração Regional e unidade sulamericana e caribenha de CLACSO. Prêmio Jabuti de 2007, livro do ano não ficção, pela coordenação da Latino-americana; enciclopédia contemporânea de América Latina e Caribe. Principal Publicação: Globalização, dependência e neoliberalismo na América Latina. Boitempo, 2011, 367p. 
